Arteterapia. Papeles de arteterapia y educación para inclusión social ISSN-e 1988-8309

https://dx.doi.org/10.5209/arte.62543

\title{
Supervisión en arteterapia: un espacio de confluencia entre el ver y el hacer
}

\author{
María Montero-Ríos ${ }^{1}$, Christophe De Vareilles², Ana Hernández Merino ${ }^{3}$
}

Recibido: 27 de noviembre de 2018/ Aceptado: 28 de marzo de 2019

Resumen. Las demandas en supervisión se dirigen a completar dudas y lagunas de tipo teórico, otras son metodológicas y prácticas, qué hacer y cómo se hace. Otras son en relación a la necesidad vincular, de reasegurarse e ir interiorizando modelos de referencia, no sólo conceptuales, sino también del hacer propio en arteterapia. Desde la posición de supervisores, escuchamos, devolvemos, señalamos, acogemos las emociones y la fragilidad de quien se expone, y en ello se refleja nuestra manera de hacer y estar en la sesión y en ese sentido es una referencia del arte de la terapia. En este artículo nos hacemos preguntas sobre qué es supervisión, que aprendemos a ver en supervisión, qué se pone en juego, dónde pone el foco el supervisor/a, qué actitud tiene, o qué transmite.

Palabras clave: Supervisión, arteterapia, encuadre, creación acompañada, psicoterapia.

\section{[en] Art therapy supervision: a space of confluence between seeing and doing}

Abstract. The demands on supervision are aimed at filling doubts and gaps of a theoretical nature, others are methodological and practical, what to do and how to do it. Others are in relation to the need to link, to reassure and go internalizing reference models, not only conceptual, but also to do own art therapy. From the position of supervisors, we listen, we return, we point out, we welcome the emotions and the fragility of the person who is exposed, and in this our way of doing and being in the session is reflected and in that sense it is a reference of the art of therapy. In this article we ask ourselves questions about what supervision is, what we learn to see in supervision, what is put into play, where the supervisor puts the focus, what attitude he has, or what he transmits.

Keywords: Supervision; art therapy; framing; accompanying creation; psychotherapy.

Sumario. Introducción. 1. ¿De qué hablamos cuando hablamos de supervisión? 2. ¿Por qué supervisión en Arteterapia? 3. Supervisión: un espacio donde aprender a ver. 4. Lo que la supervisión pone en juego. 5. ¿Dónde pone el foco la supervisión? 5.1. La supervisión en Arteterapia incluye distintos planos de narraciones. 5.2. La supervisión aporta una mirada capaz de generar una dinámica de cambio. 5.3. Es parte de la formación de la supervisión el trabajo de reflexión. 5.4. Es parte de nuestra tarea como supervisores llegar a ver al otro ausente. 5.5. En supervisión proponemos estrategias que permitan

1 Psicóloga especialista en Psicologia Clínica. Arteterapeuta. Pedagoga. Supervisora. Docente y miembro del equipo directivo del Master Arteterapia UPV. Presidenta del IDECART. Asociada a Murart.

E-Mail: m.mr@mac.com

2 Artista, filósofo y arteterapeuta, coach y arteterapeuta, Supervisor (individual y grupos); co-fundador y Profesor del Master del arteterapia de la UPV. Miembro del IDECART

E-Mail: christophe.de-vareilles@laposte.net

3 Dra en Bellas Artes, Arteterapeuta, Terapeuta Ocupacional en Salud Mental (Agència Valenciana de Salut). Supervisora de Arteterapeutas. Codirectora Máster de Arteterapia de la Universitat Politècnica de València. Miembro fundador de MURART y de IDECART.

E-Mail: arteterapia@upvnet.upv.es 
acercar las dinámicas subjetivas e inconscientes. 5.6. Proyecto de investigación. / Obra respuesta. 5.7. Supervisión y competencias profesionales. 6. ¿Qué transmite el supervisor en la supervisión? 7. La actitud del supervisor. 8. A modo de conclusión, una última definición. Bibliografía.

Cómo citar: Montero-Ríos, M.; De Vareilles, C.; Hernández Merino, A. Supervisión en arteterapia: un espacio de confluencia entre el ver y el hacer en Arteterapia. Papeles de arteterapia y educación para inclusión social 14, 2019, 163-183.

\section{Introducción}

En este trabajo queremos plantear algunas líneas de reflexión sobre la supervisión desde el marco del arteterapia. Y queremos hacerlo tanto en cuanto profesionales con un claro interés por activar desde el IDECART espacios vinculados a la formación permanente, como desde nuestra dimensión de docentes responsables de la supervisión de la práctica en el Master de Arteterapia de la UPV. Somos conscientes de la complejidad del tema que nos ocupa, pues de alguna manera la supervisión no deja de estar en la punta del iceberg, y por debajo se asientan una serie de temas que son fundamento de la coherencia metodológica y la praxis en arteterapia. Proponemos ubicarnos desde el propio marco y encuadre arteterapéutico, siendo conscientes de que por si mismo el tema de la supervisión tiene aspectos en común con otras disciplinas con las que, si bien el arteterapia comparte planteamientos sobre todo con la orientación psicodinámica, también se diferencia.

Desde nuestra práctica, observamos como las demandas en supervisión giran en torno a completar dudas y lagunas de tipo teórico, otras son metodológicas y prácticas, sobre qué hacer y cómo se hace. Otras tienen mas que ver con la necesidad vincular, de reasegurarse e ir interiorizando modelos de referencia, no sólo conceptuales, sino también del hacer propio en arteterapia. Desde la posición de supervisores, escuchamos, devolvemos, señalamos, acogemos las emociones y la fragilidad de quien se expone, y en ello se refleja nuestra manera de hacer y estar en la sesión. En ese sentido la supervisión es una referencia del arte de la terapia.

\section{1. ¿De que hablamos cuando hablamos de supervisión?}

Es evidente que estamos hablando de lo que observamos que acontece en la relación triangular entre la obra y el proceso de creación, el arteterapeuta y las personas que acompaña. Pero, al hablar de supervisión, también estamos incluyendo otros aspectos menos visibles y mas difíciles de observar, que comprenden todas aquellas inquietudes, preocupaciones, emociones, tensiones, intuiciones, dudas o reflexiones que se ponen en juego en la relación. La supervisión es por ello un espacio donde confluye lo didáctico y lo clínico, el aprendizaje de la metodología y el encuentro con las emociones que se manifiestan en la relación, y, por ello se torna no sólo tan particular, sino también tan complejo. Pues moviliza no solo la capacidad de pensar, sino también de pensarse. (Coll, F.J.; Hernández, A. 2016).

Casement $(1985)^{4}$ propone como objetivo de la supervisión el favorecer el desarrollo de esta mirada interna un "supervisor interno", como un camino hacia la

4 Citado en Delourme. A, Marc.E et al. (2007) 
interiorización del discurso y la consolidación de una identidad profesional mas autónoma y autocritica. Remarca la idea de progresión y proceso desde el momento inicial del aprendizaje, en que vamos progresivamente internalizando, absorbiendo conocimientos y referencias que provienen del exterior; hasta el momento en el que llegamos a construir e integrar una figura interna propia, en la que apoyarnos y sostenernos.

La palabra supervisión ya de entrada nos confronta con una línea vertical, de aquello que se sitúa sobre, arriba y por encima. Lo que nos recuerda que la "supervisión" es también uno de los poderes de "Superman", capaz de ver a través de paredes y montañas, con esa visión de larga distancia que alcanza kilómetros y varios lugares simultáneamente... Con ello queremos decir que la supervisión puede ser un espacio favorecedor de cierta omnipotencia. Y que en este subir y elevarse, más allá de la cuenta, podría alagarse tanto nuestro narcisismo, que parecería que el/ la propio supervisor/a con sus emociones y vivencias estuviese en otro plano. Como si quedará protegido en las alturas, ajeno a lo que le ocurre dos pisos mas abajo. Como supervisores sabemos que, aunque esta no sea una relación simétrica, ello no quiere decir que carezca de influencias mutuas, y suponga un alto nivel de implicación personal y emocional para el supervisor. La función del supervisor la hemos de valorar sobre cuánta congruencia se pone en juego en este encuentro entre subjetividades. (Rogers 1961)

Nos reconcilia con la palabra, el hecho de que también se une estrechamente al sentido de mirar con mayor o diversas perspectivas. La supervisión es un espacio donde la visión gana en amplitud y abriendo el campo gana asimismo en profundidad gracias a la distancia tanto de la mirada que nos da el otro, como la que da la experiencia. Es por ello un espacio de encuentro intersubjetivo, donde la supervisión aparece como un espacio de co-creación e influencias mutuas en un diálogo constante y reciproco que pone en juego distintos procesos intrapsíquicos por parte tanto del supervisor como del supervisado.

En este sentido, (Gilbert, M., 2007:79) $)^{5}$ destaca como los objetivos de la supervisión se apoyan en distintos conceptos para tener en cuenta: El concepto de la "función reflexiva" (Fonagy et al, 2002), la noción de la "perspectiva de la tercera persona" (Whright,1991) y el concepto de "inclusión" (Buber,1923) y (Gilbert, M. 2007: 79). Esta misma autora remarca la idea en la supervisión de: "los dos participantes contribuyen a la co-creación de la relación". Cada uno de ellos aporta al encuentro sus propias experiencias internas tal como se inscriben en su propia historia personal y en el presente de su contexto: es decir, "en un movimiento continuo de influencia reciproca y mutua" (Stolorow \& Atwood,1992:18). Tal representación de las relaciones humanas acepta que la realidad personal está siempre "co-determinada por la relación y por el significado único que cada individuo aporta al encuentro" (Gilbert, M. 2007:78).

También el concepto de co-visión tal como recoge Muro, J. et alt (2017:444) de Pichón Rivière:

El/la Supervisor/a como Covisor es un agente en la producción colectiva de conocimiento, como aquel que no sólo induce dudas si no que junto al grupo intenta encontrar soluciones. En términos más sujetos al quehacer del supervisor, desde la idea de "covisión" se asocian a elementos de la escuela de Pichón Rivière para 
pensar un funcionamiento grupal dentro de un proceso de aprendizaje y de desarrollo de autonomía por parte de los sujetos en formación. Desde esta escuela se analiza la idea del coordinador de grupo operativo como copensor de la dinámica y producción del grupo al que acompaña.

\section{2. ¿Por qué supervisión en Arteterapia?}

Entendemos el Arteterapia como una disciplina que además de un campo de aplicación psicosocial tiene también una vertiente clínica. De ahí que quizá una de las primeras preguntas que nos podemos hacer, es cómo repercute esta diferencia de marco según donde ponemos el foco, la mirada, la atención. Encontramos que los proyectos más abiertos, menos estructurados del ámbito educativo, o en ciertas instituciones donde las derivaciones en frío pueden dañar el encuadre, generan una desubicación que añade complejidad al marco psicosocial aparentemente menos conflictivo. En cambio, los proyectos en centros de salud mental, o distintos servicios de los hospitales, siendo mayor la gravedad de la problemática, se sitúan en la estabilidad del marco clínico preestablecido por el sistema, lo cual permite una mayor calma y un menor desasosiego del arteterapeuta principiante. Nos parece importante, en este sentido, tener en cuenta las distintas profesiones y especialidades de base de la que provienen los arteterapeutas; educación, psicología, arte, ciencias sociales, medicina, enfermería, terapia ocupacional etc. Cada una conlleva un cierto sesgo profesional que se manifiesta a la hora de decidir a qué doy importancia, y hacen aparecer ciertos rasgos ya sean educativos, interpretativos, asistenciales, estéticos en función del bagaje y la experiencia previa.

En cuanto disciplina pensamos que el Arteterapia propone un encuadre y metodología propia que la diferencia de otras. La entendemos como una vía de introspección a través de lo simbólico, de acceso y enriquecimiento de la subjetividad, que se concretiza y toma forma en un proceso de creación, ya que se establece en el interior de una dinámica relacional. Por similitud, en psicoterapia el centro del análisis gira en torno a la persona, sus vivencias conscientes o reprimidas, su biografía, los distintos momentos significativos de su historia, sus defensas, contradicciones, conducta, etc. Así, el psicoterapeuta se apoya en los recuerdos, sueños, asociaciones, dinámicas transferenciales, estudia las defensas, señala, interpreta, toma como arte la palabra, los significados, los silencios, los lapsus, lo lógico y lo analógico del discurso, el analista escucha, interpreta y devuelve, analiza.

En Arteterapia en cambio, no interesa tanto el análisis, la devolución o la proyección, sino la sorpresa, de lo nuevo. Nos centramos en lo que la obra nos descubre, lo que nos produce la pelea con el material, la sensorialidad que nos conecta con aquello que es difícil de nombrar y nos conmueve, y de manera particular el sentido imprevisto que la obra nos retorna. Para ello la actitud ha de ser diferente. Dice Dalley, T.:

"El proceso práctico de crear algo entabla un diálogo con el propio ser. La conclusión de este diálogo puede considerarse como una formulación concreta ante el mundo. En cuanto herramienta terapéutica, la forma artistica -exclusiva del individuo-suministra un centro para la discusión, el análisis y la autoevaluación $y$, puesto que es concreta, actúa como un registro de esta actividad que no puede negarse, borrarse u olvidarse. También sobrevive a lo largo del tiempo y por lo 
tanto sirve como índice y elemento de comparación entre el pasado y el presente" (Dalley, T 1987: 17).

El arteterapeuta facilita a través del setting y la relación vincular las condiciones para esta aventura de lanzarse a lo desconocido de uno mismo, a explorar la libertad de crear y encontrar significados que den un nuevo sentido a lo propio, generando un espacio potencial altamente reparador. En Arteterapia el centro del eje se ha desplazado a la relación de la persona con la producción, y a lo acontecido en el triángulo persona -producción artística- arteterapeuta. Y el triángulo, ya sabemos nos lleva de la mano al mundo de las irregularidades, del movimiento, de múltiples juegos de aproximación y distancia, tensiones, equilibrios y desequilibrios, ajustes y reajustes que pondrán en brete la flexibilidad y rigurosidad del arteterapeuta. Del yo en primera persona pasa al él, y hacemos un salto que nos parece altamente significativo, y a la vez muy complejo.

Una particularidad del Arteterapia, también un privilegio, es esa oportunidad de estar presentes acompañando ese estado anímico tan particular que acontece en el proceso de creación. Ese lugar similar al juego, al sueño que como diría (Winnicott. D.W. 1971) se encuentra en medio de la conciencia y lo inconsciente. El hacer como puente de la realidad, que nos concretiza y da forma a los deseos. Al tiempo que nos pone delante de la falta. De aquella diferencia entre lo que hemos imaginado y lo que la obra nos devuelve, siendo la falta un motor para la creación, aquello que nos impulsa a la búsqueda. Tendremos que aceptar que la forma sea modulada en el paso de la imaginación a la realidad, de lo posible a lo real hay un duelo y una renuncia, también una libertad y una plenitud, si. ¡También!

"Lo posible emerge en el límite de lo imposible. En este tiempo de creación, el límite entre lo posible y lo imposible es vago, borroso, uno puede precipitarse en lo imposible. Pero si el sujeto insiste, continúa su búsqueda; en algún momento nuevas formas pueden surgir, aparecen nuevos objetos, y esos nuevos objetos habrán realizado la experiencia de arroba al espacio de abajo" Fiorini.H. (2006: 30)

La creación se da en presente y al mismo tiempo que creamos, nos creamos, como dos planos que entrelazan un movimiento interno y externo. De hecho, durante la creación observamos esta mayor permeabilidad, las imágenes se proyectan con mas espontaneidad y el arte permite expresar y equilibrar conflictos reprimidos, temidos e inaceptables. Precisamente por ello, como dice Dalley. T (1987:15)

"La actividad artística proporciona un medio concreto no verbal a través del cual una persona puede lograr una expresión al mismo tiempo consciente e inconsciente, y que puede emplearse como valioso agente de cambio terapéutico".

\section{Supervisión: un espacio donde aprender a ver}

Cuando dos personas se encuentran en el interior de una relación, en cierta manera, podemos decir, que estamos ante un diálogo de ciegos. En arteterapia aquel que crea sólo ve una pequeña parte de sí mismo, sin saber o tener control de la globalidad de 
lo que está expresando. Quien acompaña, verá tan solo una pequeña parte de la compleja trama de matices que subyace y expresa el otro, donde aparecerán sólo algunos rasgos de todo lo que el arteterapeuta esperaba ver cuando planteó sus propuestas e intervenciones. En esta relación que se establece en el aquí y ahora, tampoco será totalmente consciente de lo mucho que dice con sus silencios, distracciones, o la espontaneidad de sus gestos. Nuestra profesión. Se desarrololla en esta parcial oscuridad.

El encuentro no está prefijado y es único, se está formando en presente, en el juego de dos creadores que se responden entre si, sin tener mucho tiempo para pensar en lo que hacen, generando complicidades, rituales, rupturas y toda una serie de códigos. La relación arteterapéutica aparece entonces como una obra improvisada que resulta fascinante cuando, como sucede en la supervisión, podemos volverla a leer en retrospectiva.

En la supervisión el arteterapeuta nos trae su mirada. Evoca el trabajo realizado en el taller, nos hablará de la persona que acompaña, de lo "que hace" y de si esta se sintió asombrada, indefensa, estimulada, indiferente, ajena etc. al observar su propia producción. Nos comentará qué sucedió en la relación, su forma de animarla, las emociones que surgieron al acompañar el proceso creativo (admiración, decepción, irritación, alegría, motivación, angustia, aburrimiento, desconcierto, etc.), y en este sentido, qué fue lo que señaló y qué no. Seguramente también nos hablará de cómo afrontó la tentación de analizar o desvelar el misterio de la creación, de la dificultad de no forzar el ritmo y provocar situaciones, o por el contrario detenerlas. Es decir, lo ajustado de sus intervenciones y de sus dudas. La supervisión es una actividad que requiere tiempo para que todos estos matices encuentren su espacio, y hagan visibles las particularidades del encuentro, haciendo emerger la forma propia de cada relación. En ese esbozo que va dibujando la dinámica relacional, será precisamente donde los supervisores podremos ver hasta qué punto se deja espacio y protagonismo en el terreno de juego que conduce al desarrollo personal, o se está interfiriendo y llevando el proceso hacia un sin sentido que acabará haciendo fracasar el proyecto, agotando a los dos.

Recordamos que Winnicott. D.W (1971) en Realidad y juego nos habla precisamente de esto, cuando dice que el objetivo de la terapia "es acompañar al paciente de un estado en el que no pueda jugar a un estado en el que pueda jugar". Entendemos que esta idea forma parte del núcleo que define el arteterapia, pero también de los objetivos de la propia supervisión; mantener y recuperar esta libertad de jugar que el arteterapeuta a veces puede perder. En este sentido podemos entender al arteterapeuta que estamos supervisando como alguien que juega y contemplar nuestra función de supervisores dentro del juego para ayudarlo a jugar más, para encontrar placer en las respuestas del otro, aunque puedan ser desestabilizadoras, para no perder su propia inventiva y dejarse caer, o desaparecer, retirándose cuando sus propuestas sean rechazadas, o ante los repetidos fracasos. La supervisión aparece pues como este espacio donde limpiar y limar los obstáculos que se oponen al movimiento necesario para acceder a la sutilidad de ese estado lúdico. Aligerar el peso ante lo que no hicimos, lo que no fue escuchado, o apreciado, también ante aquellas palabras y comentarios desafortunados de los que no nos dimos cuenta, o la sensación de absurdo ante lo que el otro comprendió tan diferente a lo que yo dije, (o intentaba decir). 
Encontrar y mantener la capacidad de jugar, es una cuestión que nos acompañará toda la vida en lo personal y en lo profesional. ${ }^{6}$

"La psicoterapia se realiza en la superposición de las dos zonas de juego, la del paciente y la del terapeuta. Si este último no sabe jugar, no está capacitado para la tarea. Si el que no sabe jugar es el paciente, hay que hacer algo para que pueda lograrlo, después de lo cual comienza la psicoterapia. El motivo de que el juego sea tan esencial consiste en que en él, el paciente se muestra creador." Winnicott D.W $(1993: 11)$

Por eso aprender a defender nuestra libertad supone perder el miedo a nosotros mismos para evitar que nuestras emociones y puntos ciegos impulsen nuestras actitudes y respuestas. Dar la bienvenida a nuestros estados internos, escucharlos, saber cómo tenerlos en cuenta sin que nos encarcelen, constituye el tema esencial de la libertad en la relación: la libertad interior del arteterapeuta no es algo que pueda enseñarse, es una actitud que ha de experimentarse y ser trabajada con regularidad.

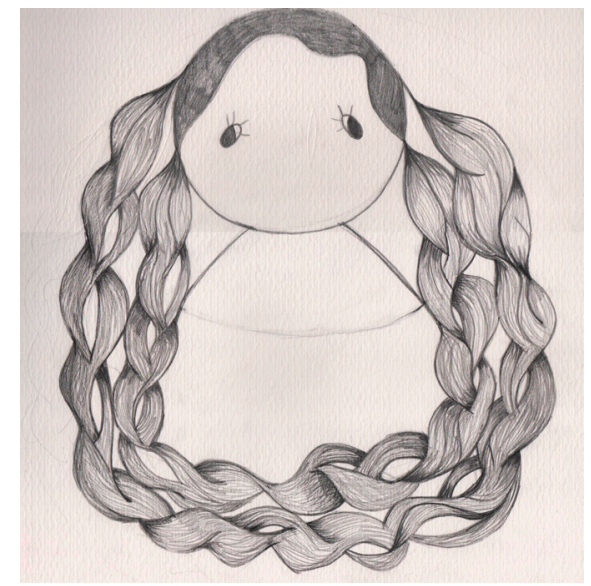

Cualquier propuesta de creación es una apertura al diálogo y una libertad: y sabemos que hay mil formas de responder a esta invitación a crear. Por ejemplo, para una persona trabajar en un formato mural puede ser una experiencia liberadora, para otra, un desafío humillante. No todo es válido, cada intuición habrá de verificarse de acuerdo con el momento, la persona y el contexto. Incluso responder a las demandas de la institución de exponer obras realizadas en el taller, puede ser una experiencia dentro de un proyecto de ocupar un lugar visible junto a los otros. El arteterapeuta ha de encontrar desde donde colocarse, es decir el encuadre interno desde donde mirar. Debe preguntarse: ¿En el caso de exponer las obras generadas en el taller, qué es lo que se quiere mostrar: al artista, al enfermo, al estigmatizado o al marginado? ¿Hasta qué punto negamos el sufrimiento, o lo idealizamos, o lo descontextualizamos? ¿Nos dejamos seducir por el artista y negamos a la persona? ¿Pretendemos revalorizarla ante los demás a través de su arte? ¿O, por el contario es el arteterapeuta quien pre-

6 Imágenes de este artículo han sido realizadas por Sefa Rodríguez (2018) para el IDECART. 
tende exponer sus conocimientos técnicos o demostrar el valor y eficacia de la propia arteterapia? ¿Servimos a la imagen de la institución, mostrando cómo se preocupa por aquellos que sufren?

Permite la supervisión ver la relación en su contexto y complejidad, y así evocar otros temas aparentemente no tan relacionados con el proceso de creación, pero que indudablemente influyen en él y nos tocan. Por ejemplo, la relación del taller con el resto de la institución en aspectos tan concretos como su ubicación geográfica, su inscripción en la arquitectura. La diferencia de situar el taller en un sótano o en el luminoso octavo piso, en el vestíbulo o en un lugar más adecuado para una experiencia privada. ¿Cómo se incorporan o no las obras del taller en el espacio institucional, si se hace con exposiciones, murales o, por el contrario desde el secreto o la confidencialidad? Es también interesante reflexionar sobre el tipo de relación entre el arteterapeuta y otros profesionales, si existen tensiones o una cordial colaboración en una convergencia de disciplinas. Cuestiones que nos llevan a ser mas conscientes de la interacción entre los distintos sistemas que nos circundan e influyen, condicionantes a veces tan habituales y difuminados que parecen no existir, pero que sin duda tienen su repercusión en el proceso arteterapéutico.

En el proceso creativo se ponen en juego simbólicamente recursos de significados muy diferentes. Por ejemplo, para unir dos piezas se puede pegar con cola, grapar, coser, anudar, fundir, y... se puede coser con hilo, cuerda, lana, alambre, plástico. ¡Cuánto detalle!, ¡Cuánta información!, ¡Cuánta riqueza! Cada material tiene su propio lenguaje y su propia flexibilidad o resistencias. Dureza o fragilidad. Cómo unimos y cómo separamos, metáforas de nuestro propio funcionamiento que nos pueden ayudar a poner palabras, a construir pensamiento, a enriquecer nuestro mundo simbólico. Al señalar estas cuestiones, al ayudar a asociar incidimos en el trabajo del arteterapeuta. De ahí la importancia y la pertinencia del momento justo, pues si se adelanta en el proceso al propio participante puede como sabemos, desplazar su protagonismo del terreno de juego corriendo el riesgo de frenar o distorsionar su creación.

\section{Lo que la supervisión pone en juego}

Sostenemos que la supervisión pretende activar la capacidad de pensar, actuar y reflexionar, siendo conscientes de que en una relación que se establece en el aquí y ahora nos encontraremos demasiado implicados, demasiado cerca y dentro para poder pensar con objetividad. De ahí que sean tan importantes los momentos anteriores y posteriores que nos permiten, ya desde una cierta distancia volver la vista y mirar cómo se fue desarrollando el proceso de arteterapia. Creemos que no es fácil reflexionar públicamente sobre uno mismo, hace falta un cierto grado de humildad y honestidad, jtambién una pizca de humor!

La reflexión supone una distancia, para vernos un poco alejados de nosotros mismos como forma de ganar amplitud y perspectiva que nos permita ser mas conscientes de nuestra propia subjetividad. El hecho de nombrar, de poner palabras a lo acontecido ayudará a ser más consciente y crítico o crítica. Queremos remarcar, una vez más, que no se trata de reflexionar para censurar o controlar, sino comprender, para ser mas libres, para implicarnos y ser capaces de arriesgarnos y de jugar. En supervisión, la reflexión nos acerca a conocer nuestros errores para evitar volver a 
reproducirlos, y por ello muchas veces nos invita a modular y limitar nuestra conducta, a ser conscientes, capaces de detener nuestros impulsos, a frenar nuestra espontaneidad, y a hacerlo como una forma de dejar espacio y abrir campo a que surjan otras posibilidades.

Es esta una posición necesaria tanto para evaluar como para valorar nuestro trabajo, para estar en contacto con uno sin perder al otro, y estar en contacto con el otro sin perderse uno. Y en esta mirada de gran angular incluimos también el entorno y los sistemas que nos rodean.

La supervisión nos parece realmente importante, entre otras cosas pues quien no está acompañado se coloca asimismo en una situación de riesgo cuando es el que acompaña a otro. Es decir, la transferencia, ya sea esta negativa o positiva, será más peligrosa y poderosa cuanto más sutil e ignorada sea.

Como arteterapeutas, profesionales de la salud o incluso como formadores, somos mucho más sensibles de lo que nos atrevemos a creer a la forma en que los otros nos tratan y perciben. Si algo no va bien, o quizá sencillamente no sale como esperábamos. Si fracasamos, o somos motivo de crítica es difícil que al mismo tiempo no nos sintamos profundamente cuestionados. ¿Qué haremos entonces con esa agresividad que se dirige hacia nosotros? ¿Con el desaliento que siento crecer en mí? ¿Y cuándo recibimos el agradecimiento, el interés, las sonrisas en esos ojos que se maravillan, de sus propios descubrimientos? ¿Y si en ese caso, nos dejamos envolver por esa imagen positiva y agradable que nos devuelven de nosotros mismos?

Ciertamente sea cual sea, la actitud del otro, no deja de ser una fuerza potente que nos puede distraer y hacernos salir de nuestro lugar para creernos mucho más indispensables de lo que realmente somos, o por el contrario, mucho más impotentes de lo que realmente somos.

Y por este camino, embarcarnos en situaciones similares a las de la película de Milos Forman (1975) "Alguien voló sobre el nido del cuco".

La supervisión nos permite ver las trampas y los callejones sin salida en los que sin darnos cuenta fuimos cayendo, las peligrosas arenas movedizas de la transferencia positiva, las recurrentes fugas que nos protegen de la destructividad del otro, y de la nuestra, que construye el alto muro que niega nuestras propias emociones y nos deja encerrados en la ceguera de lo parcial. A nuestro modo de ver, todas ellas son emociones valiosas, ya que permiten que evaluemos la importancia de los problemas que aparecen en la relación, pero sabemos también que es difícil poderlos desentrañar solos y por nuestra cuenta; este acompañar al otro en su quehacer es otra de las funciones del espacio de supervisión.

Hay una imagen sugerente en el cuento de La Bella durmiente ${ }^{7}$, el príncipe tras una eternidad de 100 años llega, y lo hace simplemente porque ha llegado el momento. El príncipe no es el arteterapeuta que acompaña, tampoco el supervisor, el príncipe es aquello que devuelve la vida a la vida. Y no viene a caballo, sino la mayoría de las veces de la mano de una frase, una mirada, algo pequeño que permitió anclaje y darse cuenta. ¡Nunca somos el príncipe del otro, pero, ... ¡Cómo nos gustaría poder ser el personaje!. ¡Y son tantas las personas que andan en busca de un príncipe (o princesa) que les despierte!. El otro tiende a ponernos en ese lugar, no sólo del salvador, sino del responsable de su vida.

(donde encontramos una inagotable reserva de imágenes sobre los distintos estados emocionales y situaciones existenciales) 
Algunas actitudes de las personas que acompañamos en el taller de creación, o en la supervisión, son mas costosas y difíciles de sostener, en particular si vienen de la mano del enfrentamiento, la oposición y la negatividad. De ahí que sea importante alzar un poco el vuelo, levantar la mirada, para ver qué se dice en lo que no se dice. Por ejemplo, negarse a crear es una respuesta. Saber decir "no" no es un desafío, puede ser también una creación y un ejercicio de libertad. Hacer algo que no sea la consigna propuesta, es un mensaje complejo, no sólo una "desobediencia". Es también un reto, y por eso una invitación al arteterapeuta a abrir su capacidad de comprender. No hablar, no contestar, no participar, puede ser también la oportunidad de activar el diálogo tónico que sostiene la presencia, que nos permite acceder a una comunicación no verbal, a otros niveles de lenguaje y resonancia cuando la persona nos cerró la puerta de la palabra.

El proceso de creación no deja de ser una creación en la que aparecen giros, búsquedas, silencios, tensiones. El Arteterapeuta que acompaña el hacer del otro, no puede ser ajeno a la repercusión que tanto el propio proceso, como el resultado golpea sobre su sensibilidad artística y en especial sobre los valores sociales que condicionan nuestros gustos y preferencias. Pensamos que una de las cosas mas importantes y quizá mas difíciles de "observar", pues se esconde entre las líneas que el/la Arteterapeuta trae a la supervisión, es precisamente la ansiedad por intervenir. Así como esas pequeñas (o grandes) contrariedades que, en relación a la obra y al proceso creativo, acontecen e influyen en el Arteterapeuta. ¿Cuántas veces esperábamos que la delicada textura azulada de esa mancha no desapareciera?, ¡y zas!, de un borrón ya no está.

Tenemos que abrirnos a estas y otras preguntas, para evitar caer en un pensamiento aislado y circular. Pensamiento que camina dando vueltas dibujando círculos, como las piedras blancas del cuento de Pulgarcito que lo traen siempre de regreso a casa, y una vez más aparecemos en el mismo sitio. Pero, no olvidemos que en ese lugar no hay alimento, no hay nada que comer, es la casa de su hambruna. O peor, en este dar vueltas sobre nosotros mismos quedamos aferrados a la ignorancia, o la prepotencia, y acabamos encerrados en una forma capaz de iatrogenizar o generar más patología y sufrimiento al que ya existe.

La supervisión hace posible inventar otras alternativas, recuperar el terreno de juego, de la libertad y la creación. Cuando no vemos claramente lo que está sucediendo, es poco probable que pensemos correctamente. "El sueño de la razón produce monstruos", dice Goya. Si no estamos atentas, el sueño de la razón lleva al desastre a la propia relación.

Diríamos pues que la supervisión es:

- Un espacio seguro, confiable, para vivir las emociones y defensas que se activan en el arteterapeuta durante el proceso, sea con la persona que acompaña, como con las producciones y en la propia relación con el/la supervisora (Omenat, M. 2016:72). Es decir, el lugar para reflexionar sobre la transferencia y la contratransferencia.

- Es también un espacio de aprendizaje, donde explorar, expresar dudas e inquietudes, aventurar propuestas y materiales, confirmar las intuiciones. En este sentido toma la forma de un lugar para contrastar y un espacio para la acción y el cambio.

- Es un lugar de apertura, de interiorización de referencias mientras vamos organizando y construyendo nuestro propio modelo interno. Por ello un espacio para activar las competencias profesionales que se ponen en juego bajo 
la mirada y el reconocimiento del otro, algo que no está reñido con nuestra propia originalidad, pero sirve para cuestionar los rasgos mas narcisistas del carácter. La supervisión comunica un saber teórico, pero también un saber clínico. Como dice Proctor $(1994)^{8}$, tiene una función restauradora en el desarrollo profesional.

- Reflexionar sobre la forma: La forma de la relación, actitudes, gestos, discurso, asociaciones y relatos tanto simbólicos como explícitos y verbales. También sobre la forma propia de la producción, como esta evoluciona, cuando aparecen nuevos significados, materiales y procedimientos, o cuando estamos en la repetición de los mismos y la resistencia al cambio. La relación del proceso de creación con los mecanismos de defensas subyacentes asociados a la patología o los diversos conflictos y narrativas y que se traducen al plano exterior de la producción y la relación. La aparición de nuevas formas de organización y autorregulación, de interés y significado. La obra reabre elementos no articulados de la sesión. (Schaverien, J.; Case,C. 2007:45)

Y aquí, para terminar este apartado no podemos dejar de nombrar cierta sensación que acompaña a la supervisión, la de que la supervisión (y/o el supervisor) es inútil, o de lo contrario, una excesiva necesidad que nace de que quien se siente incapaz e inútil es el supervisado. Es importante aprovechar para remarcar que la supervisión aún si contempla aspectos clínicos vinculados a la contratransferencia, no es una psicoterapia.

Como supervisores diríamos que ante los arteterapeutas principiantes, es gratificante presenciar cómo van resolviendo progresivamente este juego entre la omnipotencia y la dependencia. En los arteterapeutas experimentados, ya no tanto. Es frecuente que el arteterapeuta principiante sienta la supervisión como algo inútil, que no necesita. En parte están fascinados por lo que han aprendido, por el mundo que aparece tras la formación, por la sensación de competencia adquirida. ¡Como niños chicos que se abren al mundo! El aprendizaje es reciente, fresco aún en su memoria, tan claro que están convencidos de hacerlo bien y no ven los errores que puedan cometer. Por otra parte, el arteterapeuta experimentado puede sentir la supervisión innecesaria en la medida de que dada su experiencia cree saberlo todo, piensa que tiene ya el saber y se siente a salvo. Hay aquí algo que toca nuestro narcisismo, reconocer, pagar, necesitar a alguien para que me escuche, supone bajar de la posición del que sabe, piensa y escucha a la de ser escuchado y supervisado. Las relaciones humanas nunca son iguales, el aquí y ahora del trabajo creativo es siempre único, las emociones que se movilizan en la relación pondrán en evidencia nuestros puntos débiles cuánto más profundidad seamos capaces de alcanzar, los monstruos y temores ajenos no son tan lejanos a los nuestros, por eso la mirada del otro que nos sostiene y contiene tiene sentido a lo largo de todo el ejercicio profesional. La supervisión permanente es como el hilo de Ariadna que nos permite salir y estar a salvo tras el encuentro con el Minotauro. 


\section{5. ¿Dónde pone el foco la supervisión?}

Entonces volviendo de nuevo a las cuestiones que nos inquietan, tendremos de preguntarnos qué es lo que el Arteterapia pone en juego y dónde desde la supervisión deberíamos poner el foco. Dicho de otro modo, qué es y cómo hay que supervisar.

¿Qué es lo que el Arteterapeuta observa, qué es lo que nos trae a la supervisión, cuándo y cómo lo hace? En esos porqués se refleja la dinámica contratransferencial, sea en la relación con las personas /clientes que acompaña como con la figura del supervisor.

\subsection{La supervisión en Arteterapia incluye distintos planos de narraciones}

Quien supervisa favorece una determinada actitud más flexible para reconocer la diversidad de planos y narraciones que confluyen en el trabajo arteterapéutico que el supervisado que ha de estar atento a todos ellos. La obra respuesta y el trabajo artístico propio del supervisado se suma al relato desde la mirada, la palabra, la obra y la imagen que se trae a supervisión. En el proceso conciliamos materiales de distintos niveles de significado inconscientes y simbólicos, por ello el supervisor ha de generar estrategias que le permitan centrar el discurso y ayudar a hacer mas conscientes lo que fue ocurriendo en cada sesión. Para hacerlo nos apoyaremos en nuestra propia percepción de lo que nos trae el otro, y también de las ausencias, las elipsis o aquellas imágenes que nunca llegan, de comentarios sobre las propias emociones que se evitan, ... la distancia de la experiencia y el conocimiento nos permite ver, pero pensamos que una misión básica y fundamental de la supervisión es precisamente ésta, la de activar la mirada tanto externa como interna. Hay en supervisión algo de separar la paja del trigo, de no dejarnos invadir por la subjetividad del propio supervisado, que en su ansiedad, inseguridad o perfeccionismo puede actuar como una fuerza de camuflaje que nos impida ver al otro. Aquí tendremos que añadir aspectos mas sutiles que aparecen y desaparecen en el aquí y ahora de la dinámica relacional y que tienen que ver con los aspectos transferenciales que se han vivido con el arteterapeuta. Y, en caso de ser en grupo con los otros participantes y con las producciones de estos. Un entramado de transferencias múltiples.

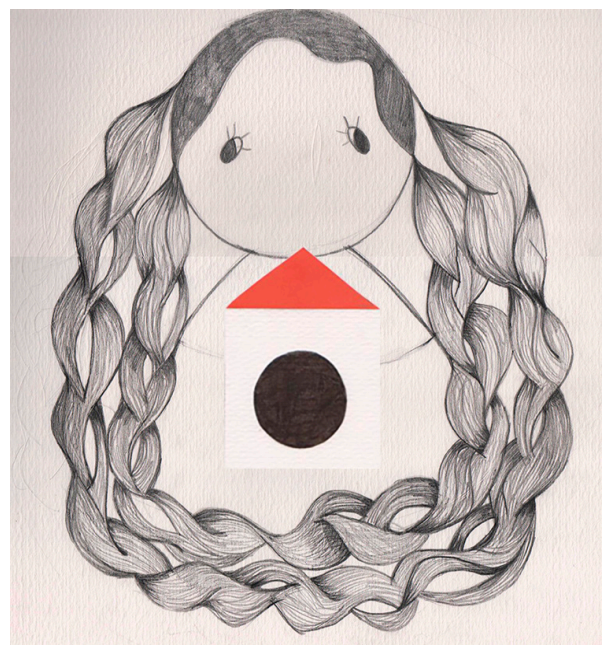




\subsection{La supervisión aporta una mirada capaz de generar una dinámica de cambio}

Pensamos que uno de los valores de la supervisión, es la idea que nos remite al holding, al espacio potencial que plantea Winnicott, D.W a la mirada de la madre suficientemente buena. En cuanto arteterapeuta supervisado, es importante encontrar una mirada que devuelva una imagen aceptable de si mismo, ya que ella aportará la seguridad y la confianza que permitirá abrir un campo de posibilidades, de oportunidad para ser. La escucha, la mirada del arteterapeuta son momentos de apertura perceptiva, de recepción. De reflexión en el sentido de Maillard. Ch (2007) de flexión sobre el me, un volver hacia mi lo sentido. Una mirada que evidentemente no es neutra, pero tampoco busca la crítica o la evaluación, en AT la escucha no tiene el objetivo principal de ser una puerta de análisis, la mirada tampoco, el análisis supone ya una distancia, en este sentido la escucha es un encuentro con el otro.

"Extraña asimetría del retrato: nunca el ojo izquierdo alcanzará su imagen si no es oblicuamente. El trayecto del mí hacia sí mismo ha de ser sesgado" (Maillard CH. 2015:106)

No olvidemos que es desde nuestro propio sentir que hemos sentido. Y, nuestra percepción puede que esté tintada de limitaciones, censura, represión, anquilosada en nuestro íntimo temor a sentir y acceder a lo inconsciente. La escucha, la mirada es un contacto directo en el sentido de que percibimos al otro a través de la autopercepción. Ninguno, ni paciente ni arteterapeuta, pueden sustraerse a su inconsciente. De ahí la importancia del trabajo personal para que el arteterapeuta mantenga los menos filtros, o al menos sea lo mas consciente posible de ellos, gracias a la reflexión que acerca a conocerse a uno mismo.

\subsection{Es parte de la formación de la supervisión el trabajo de reflexión}

Es decir, de aprender a interrogarse, a conocerse, a dialogar con uno mismo, y ser testigos de esa voz interior. Y es este un ejercicio de proximidad y distancia, de ser mas conscientes de la subjetividad, de lo inconsciente. En estas preguntas, dudas, desconciertos que hacemos, y nos hacemos, aprendemos a reflexionar sobre nosotros, a tejer puentes con lo desconocido a medida que descubrimos y nos damos cuenta. Hacernos preguntas supone acercarnos a una posición relativa, que sería lo contrario de la rigidez. Y en el espacio de la supervisión lo hacemos visible poniéndolo en palabras, imágenes y obras.

De ahí el poder de la mirada externa que ofrece el supervisor. Recreando una escena escolar sería similar al padre o la madre que escucha a la maestra diciendo el inteligente y sutil sentido de humor que tiene su hijo, y con este comentario casi de manera inmediata le devuelve una nueva imagen, deja de ver al chaval como un payaso del que se avergüenza. El cambio de mirada permite una reconstrucción de la interiorización, gracias a la cual pueden aceptar al hijo, y éste, al verse reflejado de otra manera en la mirada del padre o la madre, hace que también pueda aceptarse como alguien con valor. 


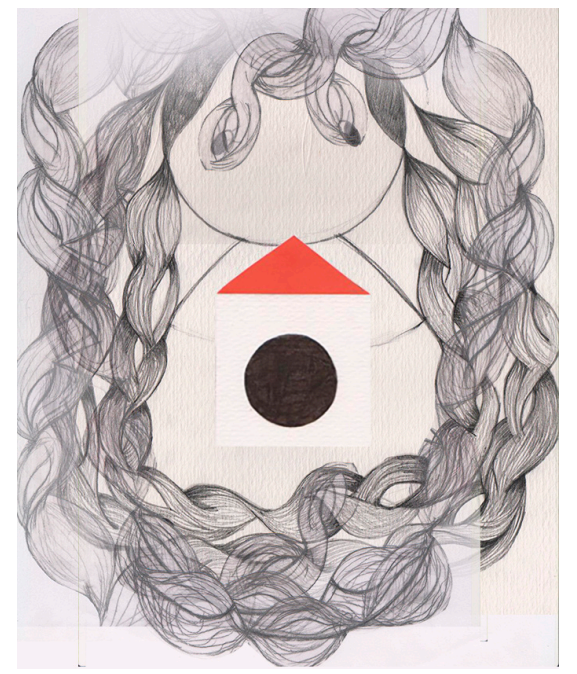

La obra del arteterapeuta como respuesta enriquece y es un peculiar acercamiento a lo que ha acontecido a nivel transferencial en las sesiones, con el interés de ser realizada fuera de ellas, en la intimidad, y por situarse asimismo a nivel simbólico supone una primera toma de distancia y de conciencia. Una aproximación al análisis de la relación terapéutica, una posible explicación del preconsciente y del inconsciente después de la sesión con el paciente. (Gracia Reyna, N. 2017)

La obra como soporte, el proceso de creación como proceso de introspección emerge y se evidencia ante nosotros (también nos pone en evidencia).

\subsection{Es parte de nuestra tarea como supervisores llegar a ver al otro ausente}

En el espacio de supervisión aparece el ausente, aquel qué nos es presentado a través del arteterapeuta supervisado, y el supervisor ha de aceptar la oscuridad de "mirar" a quien nunca ha visto, oscuridad que dinamiza preguntas e interrogantes que pueden dar paso a una mayor claridad.

La supervisión ayuda a concretar, a ver lo especifico, lo original de la persona y del proceso arteterapéutico, resalta la manera propia de su forma de crear, y facilita que se pueda relacionar con un contexto artístico histórico y cultural reintegrándolo a la comunidad. También hace más presente los ejes estructurales, las líneas generadoras del proceso, el hilo rojo, que condiciona la forma en que la persona se percibe a si misma, se relaciona con su cuerpo, contrae su motricidad, censura su espontaneidad, teme su libertad y se asienta dentro su coraza. La coraza que en el sentido de Reich W. (1948) se refiere a los mecanismos de defensa que acabamos incorporado a nuestra identidad e impide volver egodistónico lo que percibimos como egosintónico. Es la distancia de la oportunidad y la posibilidad.

Para abrir la percepción, para captar hemos de estar dispuestos a una apertura, a una permeabilidad, a las palabras a lo que se dice, pero también a las formas al cómo se dice. Y quien supervisa, nos muestra el hacer del otro al que acompaña, y para ello pone el foco en unos aspectos $\mathrm{u}$ otros, nos propone una narrativa visual de lo acontecido, a través las imágenes elegidas. 


\subsection{En supervisión proponemos estrategias que permitan acercar las dinámicas subjetivas e inconscientes}

En supervisión estimulamos, buscamos, aquello qué se ponen en juego en la relación triangular arteterapeuta, persona y producción, las devoluciones intentan hacer mas conscientes al arteterapeuta que supervisa sus propias resistencias y defensas, es por ello una posibilidad de transformar las resistencias (Omenat, M. 2016:26).

Escuchar, empatizar, dialogar, ceder, conceder, es algo que pone a prueba en cuanto supervisores nuestra capacidad de apertura, humildad, resonancia e intuición.

Nos parece importante resaltar los puntos de apoyo sobre los que nos sujetamos para aproximarnos a entender como el arteterapeuta percibe y siente, para así intuir una imagen de lo que acontece en el proceso arteterapéutico que nos permita enriquecer, abrir, ampliar, descondicionar los prejuicios tanto sobre la persona y el proceso, como sobre uno mismo y la propia forma de acompañar.

En este sentido, las estrategias que utilizamos para el desarrollo de la supervisión son por una parte el discurso, aquello que se nos cuenta, o silencia, el diario descriptivo de lo acontecido en las sesiones a través del diario de campo y las fichas de seguimiento y evaluación, el relato personal del arteterapeuta con sus emociones, sueños, recuerdos. Por otra la narrativa visual, la historia contada por las imágenes que recogen el proceso creativo y la obra final, o las propias producciones cuando tenemos la oportunidad de verlas, y junto a ello, la obra respuesta y la propia obra artística del supervisado.

\subsection{Proyecto de investigación. / Obra respuesta}

En esta línea de ordenar y hacer mas consciente el discurso, la supervisión pensamos que ha de proponer líneas orientadas a activar un perfil investigador de quien supervisa, incluyendo, como hemos dicho, la repercusión que el proceso arteterapéutico tiene en el proyecto artístico del arteterapeuta. Como dijimos en la supervisión tanto en el Master de Arteterapia de la UPV y en los espacios de formación permanente del IDECART vemos importante ir incluyendo tanto el tema de la obra como respuesta, como un conocimiento y trabajo de introspección y desarrollo personal que parta de la experiencia del propio proceso de arteterapia. Profundizar y conocer la herramienta que estamos utilizando nos dará claves de los acontecido desde la contratransferencia.

Tenemos como hipótesis que el acto de acompañar la creación del otro en el arteterapeuta supone asimismo una movilización afectiva, que influye en la construcción de su subjetividad y contratransferencia, y puede por tanto trasladarse, sea consciente como inconscientemente, a su propia práctica artística y sensibilidad poética, reflejándose en las obras, procedimientos y técnicas utilizados, o la elección de temáticas, etc. De ahí que ya en la formación del master como en la supervisión permanente, vayamos introduciendo cuestiones sobre lo que está creando ahora, los trabajos, procedimientos, líneas de motivación e interés, las resistencias y bloqueos de su practica artística, reconociendo la riqueza de este circuito entre el proceso de creación en Arteterapia y el propio y personal proceso de creación del arteterapeuta en cuanto artista, o creador.

Y por último los talleres de arteterapia para arteterapeutas, que nos permiten reflexionar sobre variables emocionales y competencias personales y profesionales desde la propia herramienta que utilizamos. En tanto docentes sentimos que es nece- 
sario aumentar la oportunidad del conocimiento y la introspección desde ese experimentarnos con nuestra propia metodología.

\subsection{Supervisión y competencias profesionales}

Y así mismo una y otra vez comprobamos que la arteterapia nos facilita el encuadre adecuado para activar una serie de competencias personales que están en la base de las competencias profesionales, como puede ser la escucha, la buena distancia, la pertinencia o no de una intervención, la precisión etc. Pero también nos abre una puerta de introspección a través de la creación orientada al desarrollo personal y a la profundización en la práctica profesional. (Coll, F.J; Hernández, A.2016).

Resumiendo entre las herramientas que requerimos que el supervisado nos aporte para llevar adelante la supervisión consideramos interesante:

- La narrativa visual y comentarios sobre el proceso de creación (a través del diario de campo).

- La imagen de la producción durante el proceso y al final de cada etapa de su evolución, con los comentarios en el espacio del taller. (Fichas de las obras).

- La verbalización el relato consciente de lo acontecido, los temas recurrentes, los enlaces con la historia y biografía.

- La dinámica grupal con sus distintos emergentes y roles.

- Reflexiones en torno a la transferencia y contratransferencia.

- La repercusión sobre el arteterapeuta en su propio proyecto artístico.

\section{6. ¿Qué transmite el supervisor en la supervisión?}

Pensamos que una cualidad del supervisor es la de ser alguien exterior, de estar fuera de la situación, y precisamente debido a que está fuera de la relación que se le presenta, puede hacer todas las preguntas, comentar libremente, ver ingenuamente. Como el niño que dice que el emperador está desnudo en el cuento "El sastrecillo Valiente" de Andersen H. C. Esta exterioridad es un recurso de regulación en cualquier actividad donde la relación interpersonal se ponga en juego, pues cada uno forma parte intrínseca de la relación, y el riesgo de estar dentro es perder la perspectiva. $\mathrm{Ne}$ cesitamos puntos de referencia externos, mas si tenemos en cuenta a un inconsciente que toma ciertas decisiones a pesar de nosotros, y a veces en contra de nosotros.

Otra de las funciones de la supervisión es la de ofrecer un espacio en el que la persona pueda no sentirse juzgada. Ya que si no son castigados ni sancionados nuestros errores pueden conseguir ser revisitados y reelaborados. En cualquier relación, hemos de contemplar que habrá momentos en los que podemos ir a tientas, buscando, perdidos sin saber por dónde va el camino. A veces cuando nos damos cuenta de nuestra torpeza o nuestra ceguera, nos sentimos culpables y los juicios que hacemos sobre nosotros mismos pueden llegar a ser terribles y muy duros. Es importante que alguien nos reciba sin espantarse de nuestros fallos y con un poco de compasión.

Por ello, creemos que quizá la tarea principal del/ la supervisora es sobrevivir ante la frustración y el desánimo, ante la oscuridad del otro hacia si mismo, sujetando la luz de la confianza, de la mirada amable pese los errores. La segunda es mantener por encima de todo el enlace que sostiene el vínculo, que garantiza el camino de ida y de retorno. 
De ahí la cuestión ¿El supervisor que transmite en la supervisión? Para afrontar esta respuesta compleja nos parece interesante retomar las aportaciones de Nasio (2007) quien considera "la supervisión como un modo de formar el inconsciente instrumental del psicoanalista". En el articulo que lleva el mismo titulo, (y del que la siguiente traducción es nuestra) sobre la cuestión que nos ocupa de que transmite el supervisor al supervisado expone su manera de vivir:

- Su identidad de analista, es decir su entusiasmo y su orgullo.

- La relación con sus pacientes, es decir su disponibilidad.

- La relación con sus maestros, muertos o vivos, es decir su humildad.

- La relación con las ideas y conceptos, es decir su rigurosidad de su pensamiento junto a la creatividad que pueda surgir.

- El contenido más importante y más difícil de transmitir para un supervisor es la manera de vivir la relación con su propio inconsciente instrumental, es decir el arte de utilizarlo y la condición para el ejercicio de este arte: la estabilidad de su vida personal. Dicho de otra forma, el supervisor transmite a su supervisado la exigencia de una vida privada globalmente estable y satisfactoria, condición necesaria para un mantenimiento adecuado del inconsciente instrumental".

Recordemos la importancia que para este autor tiene el inconsciente en cuanto receptor y percepción, ya que define lo esencial de la acción terapéutica. Esta actitud que permite poner, al servicio del proceso analítico su inconsciente instrumental y que permite al psicoanalista "captar con su inconsciente el inconsciente del otro" (Nasio 2007: XVI)

\section{La actitud del supervisor}

Como hemos dicho, la supervisión es un proceso, y no es lo mismo cuando está se incluye durante el proceso formativo del Master, cuando el arteterapeuta es principiante recién acabada la formación, o cuando son ya años de experiencia y práctica. El marco docente del Master en Arteterpaia impone una serie de limitaciones clínicas y si cabe una mayor delicadeza a la hora de confrontar a los alumnos y alumnas con sus conflictos personales y situaciones emocionales que parecen no resueltas. Pensamos que un proyecto docente como es el master de la universidad no tiene la competencia de exigir un trabajo psicoterapéutico al alumnado, precisamente para no favorecer el acting out, al transgredir la coherencia del propio marco y encuadre. No obstante, pensamos que es una responsabilidad del Master, proponer una serie de dispositivos, como son los talleres experienciales, el grupo de palabra, la reflexión sobre competencias profesionales, las tutorías, y por supuesto el espacio de supervisión de la práctica, en el que a su vez se señala la importancia y conveniencia del proceso personal para la práctica profesional del Arteterapeuta. Todos ellos tienen como objetivo el hacer mas consciente a cada alumno/a de sus carencias, emociones y sesgos contratransferenciales. Un logro que nos anima a pensar que no vamos por mal camino, es el hecho del alto porcentaje de alumnos que durante la formación demandan y entran en análisis personal.

$9 \quad$ En Delourme. A, Marc.E et al (2007): La supervisión en psychanalyse et en psychothérapie. Dunod Paris 
En el marco de la supervisión permanente de arteterapeutas, observamos como se manifiesta un interés por ser mas conscientes de las distintas variables, las dudas están mas centradas y son mas pertinentes, y esto nos permite también como supervisoras mayor profundidad en la reflexión de aspectos personales que se ponen en juego. Algo que hacemos siempre atendiendo a la máxima de no abordar frontalmente las defensas para evitar reactivarlas. Una luz demasiado intensa sobre los ojos tiene el riesgo de cegar y quemar.

Pensamos que la habilidad del supervisor se muestra en saber hasta dónde puede llegar desde la delicadeza y sutilidad, pues lo importante, más que mostrar, es que el otro lo descubra y se de cuenta. Para ello diríamos que un pequeño toque de "la varita mágica", como en la cenicienta basta. $\mathrm{O}$, dicho de otro modo, un pequeño cambio en la tonalidad del color modifica la composición entera. Así también, un comentario, señalización, asociación, enlace lo podemos apoyar sea en la técnica, el lenguaje artístico, materiales, producción, verbalización, relación, marco conceptual, y elegir como, donde y cuando, forma parte de la habilidad y experiencia del supervisor. Una de las cuestiones que observamos y resultan más complejas es la dificultad de concretar, de tener un hilo de lo que se pone en juego, de lo latente. ¿Cuál es la demanda de la persona, para que está buscando respuestas, cuáles son sus dudas y dificultades, sus temores e impedimentos? ¿Qué es lo que necesita decir, lo que una y otra vez con formas diversas intenta decir o resolver? ¿Qué me hace sentir, qué estados de ánimo convoca en mí como arteterapeuta? ¿Qué atmosfera crea la obra?

En cierta manera estas y otras preguntas nos parecen pertinentes en la medida en que funcionan como puntos de anclaje, similar a los que utilizamos para situar la figura en el dibujo. Nos muestran una especie de radiografía existencial, como una malla octogonal en los cuadros de Picasso. Son como referencias a las que volver una y otra vez, y tienen el valor de ayudar a no perdernos entre múltiples informaciones, muchas de las cuales nos despistan y desvían. Algunas cotidianas, otras trágicas que no podrán desactivarse por mucho que se hablen una y otra vez, y obsesivamente se repitan. El Arteterapia al situarnos en el aquí y ahora, coloca también el reflejo de la angustia, el bloqueo y el sufrimiento en lo actual, y es aquí donde tantas veces observamos el comienzo del cambio y la reparación. Es importante que el arteterapeuta principiante aprecie el valor de estos dos planos y las relaciones que entre ellos se establecen. Cuantas veces la persona verbaliza el relato, las quejas y justificación de su historia; como un volver repetitivo sobre lo ya dicho, que impide avanzar hacia lo no dicho. Pero al mismo tiempo la obra (¡bendita sea!) nos ofrece y confronta con un nuevo discurso, y diríamos que aún más la obra se resiste a ser fagotizada, mantiene su propia identidad a través de los materiales, su color, fragilidad, fuerza, textura. Las obras hablan su propio discurso y no siempre dicen lo mismo que las palabras, a veces expresan una enorme seguridad con pies de barro, una gran necesidad de relación con el exterior desde una casa sin puertas ni ventanas, un temor a crecer con trazos que cuando pueden se escapan a brochazos del papel. La producción cuenta su historia desde lo simbólico y por tanto se puede contrastar para ser más conscientes de estos dos planos del discurso, para ver que es lo que me hace sentir la producción, qué significados me devuelven. No daremos nada por supuesto, lo evidente nunca es tan evidente, el plano verbal y el simbólico pueden contradecirse, o apoyarse y matizarse. Quizá la base de barro me hable del derecho a ser frágil, la casa sin ventanas de la necesidad de no abrirse de cualquier manera, de encontrar el momento, el dibujo que se escapa de aceptar los límites de la realidad. 
El arteterapeuta necesita calma y un espacio mental sin prejuicios. Es tarea de la supervisión el favorecerlo. Es ésta una labor que en Arteterapia hacemos teniendo en cuenta una de sus aportaciones especificas y valiosas, la creación nos ayuda a construir imágenes, pensar en imágenes nos ayuda a estructurar y organizar el pensamiento para poder expresarlo en palabras. Por ello entendemos que el núcleo y el desafío del trabajo del supervisor es retornar a la persona desde su propia libertad para actuar, es decir nuestro objetivo no es sólo ampliar la conciencia sino cambiar actitudes, optimizar la relación. Se trata de comprender o pensar sobre lo que acontece y avanzar un paso más hacia descubrir qué puedo hacer, qué decisiones debo tomar, o cuál es mi margen de maniobra. Es en este sentido que entendemos como un obstáculo y un riesgo el que como supervisores nos quedarnos seducidos y satisfechos por esos análisis y reflexiones tan lúcidos que hacemos, ciertamente inteligentes, pero no por ello siempre eficaces a la hora de promover el cambio

Hablando de los escollos en los que puede verse envuelto el supervisor, no podemos dejar de mencionar esa actitud que nos puede llevar a dar consejos, a dictar al supervisado la conducta correcta que debe adoptar, limitado a la persona que supervisa en su libertad de decisión, convirtiéndolo en cierta manera en el ejecutor de lo que lo que nosotros haríamos.

\title{
A modo de conclusión, una última definición
}

Por lo tanto, la supervisión puede definirse como un espacio donde la reflexión se desarrolla o expande para que la persona supervisada pueda sentirse segura al tomar sus propias decisiones. Yalom.I. D. (1984: 281) dice que "El objetivo de la psicoterapia es llevar al paciente a la etapa en la que puede tomar una decisión libre". Si bien señala que la supervisión no es ni tiene por qué ser una psicoterapia, podemos decir que lo puede compartir con la supervisión. Idea esta que reformularíamos de la siguiente manera: "El objetivo de la supervisión es lograr que la persona supervisada pueda en su trabajo tomar una decisión de una manera más consciente y libre. "Yalom.I. D. (1984:280) continúa:

\begin{abstract}
"El terapeuta debe cortejar la acción. Puede afirmar que persigue otros objetivos (profunda comprensión de sí mismo, autorrealización, comodidad) pero, como último recurso, el cambio (es decir, la acción) es la presa secreta que pretende alcanzar todo terapeuta"
\end{abstract}

Esta idea nos inspira esta nueva reformulación: El cambio (es decir, la acción) es lo explícito del contrato de supervisión.

La supervisión es un espacio también de preguntas y respuestas, pero gran parte de lo que acontece paradójicamente lo hace en un silencio de palabras y un discurso de gestos. Hay un mensaje encima de la mesa, otro que es expresión y descubrimiento de un yo, que incluso se muestra más allá de mí. Es por eso que es muy importante el tiempo de mirar juntos, el silencio de acoger lo que no tiene palabras que está cargado de emoción, de significados que se sitúan muchas veces en las entretelas de lo pequeño. Cómo transmitir este conocimiento nos parece uno de los retos de la supervisión, como crear esta atmosfera que nos permita dialogar en silencio. Y habrá tiempo, luego habrá tiempo para las palabras que sean necesarias. 
Es este un rasgo en el que a nosotros nos gusta hacer hincapié, pues a veces la relación más que acompañar al otro en su proceso se convierte en un bombardeo de preguntas e interrogantes, que nacen de la inseguridad del principiante, y no deja de ser una manera de apropiarse del espacio del otro en el sentido de Winnicott D. W. (1971). Es como si paradójicamente con la obra o el proceso no tuviésemos suficiente y necesitásemos que el otro hablara y nos contara, y también nos reasegurara poniendo en palabras lo que siente. Bajo la capa de demostrar interés por la persona lo cierto es que algunas de las preguntas que hacemos son muchas veces innecesarias, y pueden limitarnos al sacarnos del juego y la ficción. Y en este salto salimos en volandas del espacio simbólico al plano de la realidad. El proceso arteterapéutico se sitúa en el plano simbólico, recordemos es ese nuestro espacio de juego, es la puerta hacia lo desconocido, el soporte que nos lleva al darse cuenta. Cuanto mas tiempo permanezcamos en él, aunque parezca una paradoja, más tiempo estamos en casa.

El arteterapeuta ha de estar cada vez mas preparado para acoger la forma, para generar empatía desde la sensibilidad poética, para dar consistencia y valor a ese mundo interno donde asienta la subjetividad, el espacio de supervisión tiene como objetivo reforzar y estimular estas habilidades. La supervisión es también un proceso que evoluciona con el tiempo en la medida que el arteterapeuta principiante va interiorizando el discurso y la experiencia tomando confianza en si mismo. En este sentido diríamos que el espacio de supervisión también se va depurando hacia cuestiones cada vez mas concretas y esenciales.

Y es un territorio de frustración narcisista, un espacio para la humildad. Pues descubrir el qué y el por qué, quizá a veces nos venga de regalo, pero no es la intención, la producción es mucho mas que una proyección, y es en ese sentido que hemos de aceptar no saber, pues ahí precisamente reside su valor terapéutico. En el espacio simbólico podemos pensar, sentir, ver sin palabras de hecho, ello nos ayuda a poner en palabras a mostrar los significados a posteriormente ampliarlos con enlaces que tienen que ver con nuestra historia, deseos, y realidad psíquica, el cómo definirá el qué, la forma dará el sentido que tendrá significado.

La supervisión ayuda a conocerse, a aprender a interrogarse, a confiar y dudar, a saber, reconciliarse con los límites, a reconocer los deseos, frustraciones, proyecciones, es decir hacer más consciente la contratransferencia. Y por último ofrecemos en supervisión un espacio seguro donde el supervisado puede sin consecuencias y por ende con mayor libertad arriesgarse, atreverse a crear hipótesis, inventar recursos y estrategias, plantear dudas, confirmar sus intuiciones y pasar a la acción.

\section{Bibliografía}

Coll, F. J.; Hernández, A. (2016): Supervisión: la evidencia del insconsciente en el tratamiento. En VVAA (2016): Reflexiones acerca de la supervisión en Arteterapia. Colección fundamentos. Feapa. ISBN: mu-1048-2016. (pp. 15-30)

Delourme. A, Marc.E et al. (2007): La supervisión en psychanalyse et en psychothérapie Paris, Dunod.

Fiorini. H. (2006): Psiquismo Creador. Buenos Aires, Nueva visión.

García-Reyna, N. (2017). Respuesta Artística de Arteterapeutas. La Revista de Arteterapia de Metáfora, 1:1, 18-28, DOI.

Maillard CH. (2015): La mujer de pie Galaxia Barcelona. Gutenberg 
Muro, Julio; Barrault, Omar A.; Plaza, Silvia.; Díaz, Inés (2017): Supervisión de prácticas de intervención comunitaria como espacio de acompañamiento y construcción crítica. Experiencias desde la Psicología Comunitaria. Anuario de Investigaciones de la Facultad de Psicología II Congreso Internacional de Psicología - V Congreso Nacional de Psicología “Ciencia y Profesión” Año 2017, Vol. 3, N¹, 440-453 ISSN 1853-0354 www.revistas.unc.edu.ar/index.php/aifp

Nassio, (2007): La supervisión como un modo de formar el inconsciente instrumental del psicoanalista. En Delourme. A, Marc.E et al(2007): La supervisión en psychanalyse et en psychothérapie. Dunod Paris

Omenat, M. (2016): La supervisión en arteterapia. Formación continuada. En VVAA (2016): Reflexiones acerca de la supervisión en Arteterapia. Colección fundamentos. Feapa. ISBN: mu-1048-2016. (pp 65-84)

Reich. W, (1980): Analisis del carácter. Barcelona, Paidós

Rogers, C. R. (1997). Psicoterapia centrada en el cliente. Barcelona, Biblioteca de psicología, psiquiatría y psicoterapia, vol 28. Paidós.

- (2004). El proceso de convertirse en persona. Barcelona: Paidós.

Schaverien, J.; Case, C. Ed. (2007): Supervisión of Art Psychoterapy. A theoretical and practical handbook. U.K. Routledge

VVAA (2016): Reflexiones acerca de la supervisión en Arteterapia. Colección fundamentos. Feapa. ISBN: mu-1048-2016.

Winnicott D.W (1993): Realidad y juego. Barcelona, Gedisa

Yalom, I.D. (1984): Psicoterapia Existencial. Barcelona. Herder. 